\title{
Endothelial Cell Apoptosis Is a Primary Pathogenetic Event Underlying Skin Lesions in Avian and Human Scleroderma
}

\author{
Roswitha Sgonc, ${ }^{*}$ Matthias S. Gruschwitz, ${ }^{\ddagger}$ Hermann Dietrich, ${ }^{*}$ Heidrun Recheis, ${ }^{\star}$ M. Eric Gershwin, ${ }^{\S}$ and Georg Wick ${ }^{\star}$ \\ *Institute for General and Experimental Pathology, University of Innsbruck, Medical School, 6020 Innsbruck, Austria; ${ }^{\star D e p a r t m e n t ~ o f ~}$ \\ Dermatology, University of Erlangen-Nuremberg, 91052, Erlangen, Germany; and ${ }^{\S}$ Department of Internal Medicine, Division of \\ Rheumatology-Clinical Immunology, and the Department of Avian Sciences, University of California, School of Medicine, Davis, California 95616
}

\begin{abstract}
The mechanism that may cause degenerative fibrotic skin lesions was studied in situ using skin biopsies from patients with systemic sclerosis (SSc), localized scleroderma, or keloids, and at the initial disease stage in the University of California at Davis (UCD) lines 200/206 chickens, which develop a hereditary systemic connective tissue disease resembling human SSc and permit study of disease stages not accessible in humans. Frozen skin sections were analyzed simultaneously for apoptosis by terminal deoxynucleotidyl transferase-mediated FITC-dUTP nick end labeling and indirect immunofluorescence staining of cell markers with tetramethylrhodamine isothiocyanate conjugates. The results showed that endothelial cells are clearly the first cells to undergo apoptosis in the skin of UCD-200/206 chickens, a process that seems to be induced by anti-endothelial cell antibodies. In human fibrotic skin diseases, apoptotic endothelial cells could only be detected in early inflammatory disease stages of SSc and localized scleroderma. (J. Clin. Invest. 1996. 98:785-792.) Key words: systemic sclerosis • apoptosis • anti-endothelial cell antibodies • autoimmunity - TUNEL
\end{abstract}

\section{Introduction}

Systemic sclerosis $(\mathrm{SSc})^{1}$ is a multistage autoimmune disorder characterized by three morphological hallmarks in early skin lesions: structural and functional vascular and microvascular abnormalities, perivascular and tissue infiltration of mononuclear inflammatory cells, and increased collagenous and noncollagenous extracellular matrix molecules. During disease

Address correspondence to Dr. Roswitha Sgonc, Institute for General and Experimental Pathology, University of Innsbruck, Medical School, Fritz-Pregl-Str. 3, A-6020 Innsbruck, Austria. Phone: 43-512507-3101; FAX: 43-512-507-2867.

Received for publication 13 November 1995 and accepted in revised form 21 May 1996.

1. Abbreviations used in this paper: AECA, anti-endothelial cell antibodies; loSc, localized scleroderma; NWL, normal White Leghorn; OS, obese strain; SSc, systemic sclerosis; TCR, T cell receptor; TRITC, tetramethylrhodamine isothiocyanate; TSK, tight skin; TUNEL, terminal deoxynucleotidyl transferase-mediated FITCdUTP nick end labeling; UCD, University of California at Davis.

J. Clin. Invest.

(C) The American Society for Clinical Investigation, Inc.

0021-9738/96/08/0785/08 \$2.00

Volume 98, Number 3, August 1996, 785-792 progression, fibrotic destruction of internal organs such as lung, heart, kidney, and the gastrointestinal tract takes place (1-3). Fibrotic stages of SSc with the full-blown clinical symptoms often fail to exhibit prominent perivascular skin infiltration, which can always be found in the early inflammatory stage of both SSc and localized scleroderma (loSc) (4). Although great effort has been made to elucidate the pathogenesis of scleroderma, the etiology and primary pathogenetic events of this disease remain unclear. The search for the ultimate etiology of autoaggression requires animal models in which the disease is either induced experimentally or develops spontaneously. Few spontaneous animal models of hereditary scleroderma are available, e.g., the tight skin (TSK) mouse, a dominant mutant of the inbred B10.D2(58N)/Sn mouse strain $(5,6)$ and the University of California at Davis (UCD) chicken lines 200 and 206 (7-9). The homozygous TSK/TSK is a lethal mutation. Heterozygous TSK mice (TSK/+) show marked thickening, induration, and tightness of the skin as the most prominent clinical symptom. Whereas TSK/+ mice lack important symptoms of human scleroderma (5), such as the inflammatory and immunological features as well as vascular and gastrointestinal involvement, UCD-200 and 206 chickens develop the entire spectrum of SSc, i.e., vascular occlusion, severe perivascular lymphocytic infiltration of skin and viscera, fibrosis of skin and internal organs, antinuclear antibodies, anticardiolipin antibodies, rheumatoid factors, and distal polyarthritis (10-12). These chickens spontaneously develop an inherited scleroderma-like disease with an initial inflammatory stage 1-3 wk after hatching, most prominently in the comb (Fig. 1), finally leading to fibrosis with excessive accumulation of collagen types I, III, and VI in the afflicted tissues (13). The immune system seems to play an important role in the development and/or perpetuation of these lesions. UCD-200/206 chickens exhibit a severe perivascular infiltration of the skin with mainly $\mathrm{T}$ cell receptor (TCR) $\gamma / \delta^{+} / \mathrm{CD}^{+} / \mathrm{MHC}$ class $\mathrm{II}^{-}$ $\mathrm{T}$ lymphocytes, of which $\sim 50-75 \%$ coexpress $\mathrm{CD} 8$, in the papillary dermis, and TCR $\alpha / \beta^{+} / \mathrm{CD}^{+} / \mathrm{CD} 4^{+} / \mathrm{MHC}$ class $\mathrm{II}^{+}$ in perivascular areas of the deeper dermis and subcutaneous tissue (14). The relationship between these inflammatory cells, endothelial cells, and fibroblasts may be critical in the early stages of scleroderma. It has been suggested previously that there is a primary microvascular abnormality in SSc patients, but it is still unclear whether immune alterations follow or precede endothelial changes (15-17).

The aim of this study was to identify in situ the mechanisms that cause the degenerative skin lesions at the initial disease stage and to characterize the targets and possible effectors of this process. Since human patients obviously are not under medical control until clinical manifestations are fully established, the majority of these investigations were performed in the UCD-200/206 chicken, a well-established model for SSc in which these early events can be studied. In parallel, we also an- 


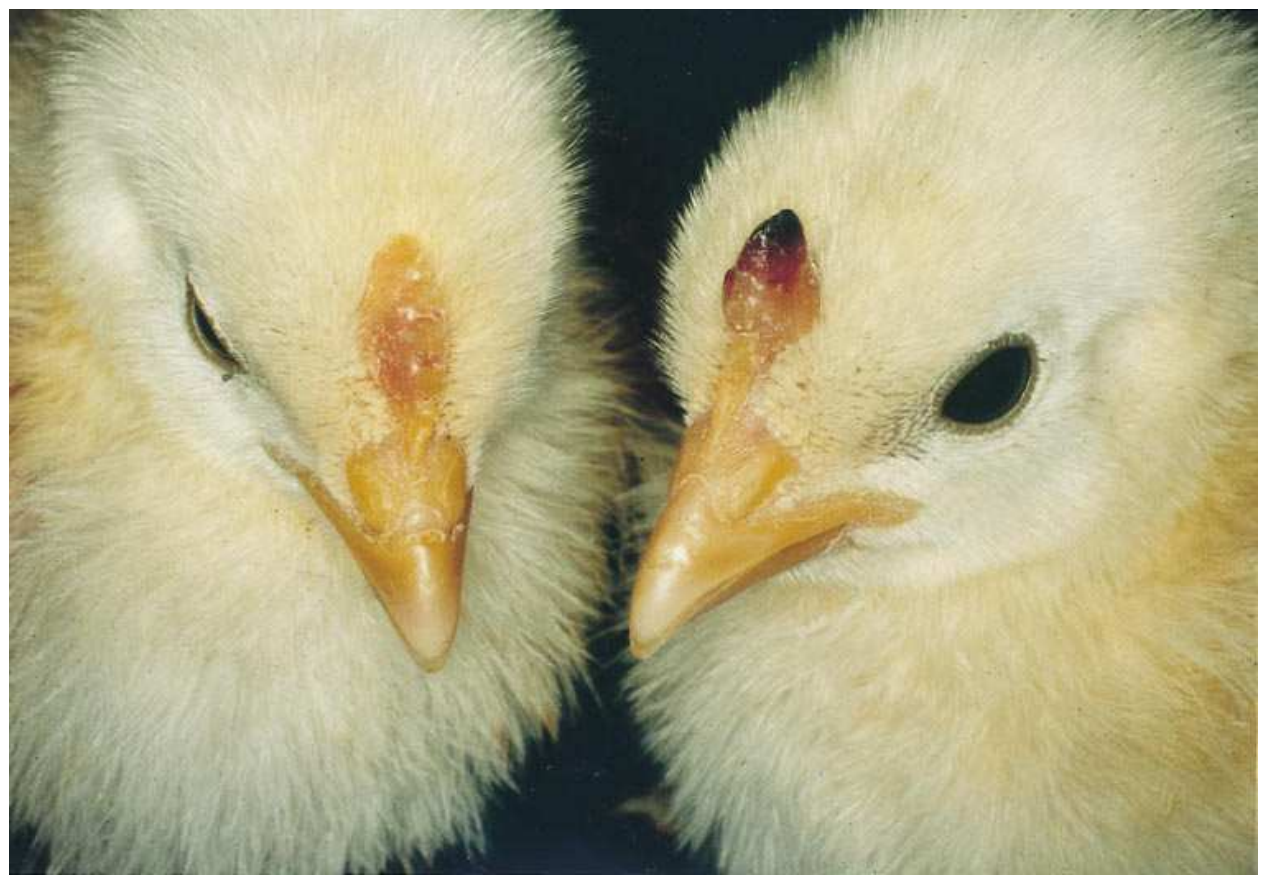

Figure 1. 1-wk-old UCD-200 chickens with combs showing edema (left) and onset of necrosis (right).

alyzed skin biopsies of human patients with SSc, loSc, and keloids. Herein, we document that a primary event in the pathogenesis of the scleroderma-like disease in the UCD-200/206 chicken is endothelial cell apoptosis, probably caused by antiendothelial cell antibodies (AECA), a finding supported by results from human skin biopsies. Understanding the pathogenetic mechanisms of scleroderma at a molecular level and identifying their targets opens new possibilities for development of more specific diagnosis and treatment.

\section{Methods}

Animals. The following strains of chickens were used: UCD lines 200 and 206, which spontaneously develop an inherited scleroderma-like disease $(7,18)$, healthy UCD line 058, which have the same MHC haplotype $\left(B^{15}\right)$ as line 206, normal White Leghorn (NWL) chickens as healthy outbred controls, and the obese strain (OS), a chicken model of spontaneous autoimmune thyroiditis $(19,20)$, as a control with an unrelated organ-specific autoimmune disease. NWL chickens were purchased from a local breeder (F. Moser, Polling, Austria). The other strains were maintained in the Central Laboratory Animal Facilities of the Medical School of the University of Innsbruck, Austria.

Patients. After appropriate consent was obtained, lesional skin biopsies were taken by oval excision under local anesthesia from 15 SSc patients at different disease stages (chronic-sclerotic stage: $n=8$; early-edematous, acute stage: $n=7$ ), 9 patients with loSc (acuteinflammatory phase), and 3 patients with keloids. For clinical diagnosis, the classification of the "Arbeitsgemeinschaft Dermatologische Forschung" (21) combined with the American College of Rheumatology (formerly, the American Rheumatism Association) criteria (22) was used (SSc I: acrosclerosis, limited disease; SSc II: ascendant involvement of lower arms and legs, limited disease; SSc III: centrosclerotic/diffuse scleroderma). Clinical diagnosis was completed and the extent of inflammatory infiltration was determined by routine histological examination. Evaluation of visceral involvement, blood and serological parameters (white cell count, blood sedimentation rate, immunoglobulins, quantification of Rose-Waaler test, titers and subsets of antinuclear antibodies, soluble ICAM-1 and VCAM-1 serum levels) were determined. The single parameters were evaluated as positive in the case that blood sedimentation rate $>40 \mathrm{~mm} / \mathrm{h}$, RoseWaaler test $>1: 20$, immunoglobulins $>16$ grams/liter, antinuclear antibodies $>1: 160$, or leukocyte count $>10,000 / \mathrm{ml}$. Patients were classified as acute inflammatory stage if more than three parameters of unspecific inflammatory signs were positive in addition to elevated sICAM-1 and sVCAM-1 serum levels (23) and prominent lymphocytic infiltration of the involved skin. Clinical examinations were performed by the same investigator (M.G.). Assessment of the skin was evaluated by a modified skin score of Kahaleh (24) using a scale from 0 to $3(0=$ normal, $1=$ slight, $2=$ severe, $3=$ extreme degree of thickening) at 15 anatomical sites (maximum score 45). Normal skin from healthy controls $(n=8)$ served as controls. Skin biopsies were snap frozen in liquid nitrogen and kept at $-80^{\circ} \mathrm{C}$ until use. Clinical data and disease stages of the patients are presented in Table I.

Antibodies and conjugates. Mouse anti-chicken CD4 and mouse anti-chicken CD8 antibodies were kindly provided by O. Vainio (Turku, Finland), and rabbit anti-chicken procollagen I was provided by R. Timpl (Munich, Germany). FITC-conjugated goat anti-chicken Ig was prepared in our laboratory. Monoclonal mouse anti-chicken TCR1 (TCR $\gamma / \delta$ ) was purchased from Southern Biotechnology (Birmingham, AL), rabbit anti-vWf was from Behring (Marburg, Germany), tetramethylrhodamine isothiocyanate (TRITC)-rabbit Ig to mouse Ig and TRITC-swine Ig to rabbit Ig were from Dakopatts (Glostrup, Denmark). All antibodies and conjugates were diluted to predetermined optimal concentrations in PBS ( $\mathrm{pH} 7.2) / 1 \%$ BSA.

Detection and characterization of apoptotic cells. Animals were killed by cardiac desanguinization under Nembutal anesthesia. Combs were removed and immediately frozen in liquid nitrogen. $4-\mu \mathrm{m}$ frozen tissue sections were incubated for $30 \mathrm{~min}$ with the primary antibody, washed $30 \mathrm{~min}$ in PBS, incubated for $30 \mathrm{~min}$ with TRITC-conjugated second antibody, and washed in PBS for $30 \mathrm{~min}$. After this standard indirect immunofluorescence test, detection of apoptotic cells was performed by the terminal deoxynucleotidyl transferase-mediated FITC-dUTP nick end labeling (TUNEL) technique (25). For this purpose, tissue sections were fixed for $20 \mathrm{~min}$ in $4 \%$ paraformaldehyde, washed for $30 \mathrm{~min}$ in PBS, permeabilized with $0.1 \%$ Triton X-100/ $0.1 \%$ sodium citrate for $2 \mathrm{~min}$ on ice, washed in Tris-buffered saline (TBS, pH 7.4) for $5 \mathrm{~min}$, dehydrated by $50 \%, 75 \%, 100 \%$ ethanol, and rinsed in chloroform. After a 60-min incubation in a moist cham- 
Table I. Clinical Data of Patients and Detection of Apoptotic Endothelial Cells in the Skin

\begin{tabular}{|c|c|c|c|c|c|c|c|c|c|c|c|}
\hline Patient & Sex/age (yr) & Therapy* & Localization of biopsy & Diagnosis/SSc type ${ }^{\ddagger}$ & Stage of the disease ${ }^{8}$ & Involvement & Symptoms & Clinical disease progression & Duration & Presence of skin infiltrates ${ }^{\mathrm{I}}$ & Apoptotic endothelial cells** \\
\hline & & & & & & & & & mo & & \\
\hline 1 & $\mathrm{~F} / 56$ & No & Lower arm inside & SSc I & Sclerotic & $S, G$ & Scl, R & + & 16 & ++ & - \\
\hline 2 & $\mathrm{~F} / 56$ & No & Lower arm foreside & SSc II & Sclerotic & $\mathrm{S}, \mathrm{G}, \mathrm{K}$ & Scl, R & $\varnothing$ & 22 & + & - \\
\hline 3 & $\mathrm{M} / 47$ & No & Finger & SSc I & Sclerotic & $\mathrm{S}$ & Scl, R & $\varnothing$ & 36 & + & - \\
\hline 4 & $F / 33$ & No & Back & SSc III & Sclerotic & $\mathrm{S}, \mathrm{G}, \mathrm{K}, \mathrm{L}$ & Scl, R & $\varnothing$ & 96 & $(+)$ & - \\
\hline 5 & $\mathrm{~F} / 40$ & No & Forearm & SSc I & Sclerotic & $\mathrm{S}, \mathrm{G}$ & Scl, R & $\varnothing$ & 50 & + & - \\
\hline 6 & $\mathrm{~F} / 53$ & No & Forearm & SSc II & Sclerotic & $\mathrm{S}, \mathrm{G}, \mathrm{L}$ & $\mathrm{Scl}$ & + & 62 & + & - \\
\hline 7 & $\mathrm{M} / 40$ & No & Backside hand & SSC II & Sclerotic & $\mathrm{S}, \mathrm{G}$ & Scl, R & $\varnothing$ & 58 & $(+)$ & - \\
\hline 8 & $\mathrm{M} / 42$ & No & Forearm & SSC I & Sclerotic & $S$ & Scl, R & $\varnothing$ & 28 & $(+)$ & - \\
\hline 9 & $\mathrm{~F} / 48$ & No & Lower arm foreside & $\mathrm{SSc} I$ & Early edematous & S & Scl, R, E & + & 5 & +++ & + \\
\hline 10 & $\mathrm{~F} / 65$ & No & Forearm & SSc II & Early edematous & S & $\mathrm{R}, \mathrm{E}$ & + & 3 & ++ & ++ \\
\hline 11 & $\mathrm{~F} / 65$ & No & Lower leg & SSc II & Early edematous & S & $\mathrm{R}, \mathrm{E}$ & + & 4 & ++ & + \\
\hline 12 & $\mathrm{~F} / 56$ & No & Finger & SSc I & Early edematous & $S$ & $\mathrm{R}, \mathrm{E}$ & ++ & 5 & ++ & ++ \\
\hline 13 & $\mathrm{~F} / 52$ & No & Lower arm inside & SSc II & Early edematous & $\mathrm{S}$ & $\mathrm{R}$ & + & 3 & +++ & ++ \\
\hline 14 & $\mathrm{M} / 48$ & No & Backside hand & SSc I & Early edematous & $\mathrm{S}$ & $\mathrm{R}$ & + & 6 & ++ & + \\
\hline 15 & $\mathrm{~F} / 60$ & No & Forearm & SSc II & Late edematous & $\mathrm{S}, \mathrm{K}, \mathrm{L}$ & Scl, R, E & ++ & 20 & ++ & + \\
\hline 16 & $\mathrm{M} / 61$ & No & Lower leg & loSc & Inflammatory & S & - & - & 18 & ++ & ++ \\
\hline 17 & $\mathrm{M} / 18$ & No & Neck & loSc & Inflammatory & $\mathrm{S}$ & - & - & 9 & +++ & + \\
\hline 18 & $\mathrm{~F} / 54$ & No & Buttocks & loSc & Inflammatory & S & - & - & 14 & ++ & ++ \\
\hline 19 & $\mathrm{~F} / 38$ & No & Abdomen & loSc & Inflammatory & S & - & - & 7 & ++ & + \\
\hline 20 & $\mathrm{M} / 30$ & No & Shoulder & loSc & Inflammatory & S & - & - & 13 & +++ & ++ \\
\hline 21 & $\mathrm{~F} / 33$ & No & Abdomen & loSc & Inflammatory & S & - & - & 6 & +++ & + \\
\hline 22 & $\mathrm{~F} / 29$ & No & Abdomen & loSc & Inflammatory & S & - & - & 11 & +++ & ++ \\
\hline 23 & $\mathrm{~F} / 52$ & No & Shoulder & loSc & Inflammatory & $\mathrm{S}$ & - & ++ & 9 & ++ & + \\
\hline 24 & $\mathrm{M} / 16$ & No & Lower leg & $\operatorname{loSc}$ & Inflammatory & $\mathrm{S}$ & & ++ & 4 & ++ & ++ \\
\hline 25 & $F / 32$ & No & Breast & keloid & & $\mathrm{S}$ & $\varnothing$ & $\varnothing$ & $\varnothing$ & $\varnothing$ & - \\
\hline 26 & $\mathrm{M} / 42$ & No & Breast & keloid & & S & $\varnothing$ & $\varnothing$ & $\varnothing$ & $\varnothing$ & - \\
\hline 27 & $F / 39$ & No & Breast & keloid & & S & $\varnothing$ & $\varnothing$ & $\varnothing$ & $\varnothing$ & - \\
\hline $28-35$ & $\begin{array}{c}3 \mathrm{~F} / 5 \mathrm{M} \\
\text { median } \\
42 \mathrm{yr}\end{array}$ & No & Upper arm inside & Healthy control & $\varnothing$ & $\varnothing$ & $\varnothing$ & $\varnothing$ & $\varnothing$ & $\varnothing$ & - \\
\hline
\end{tabular}

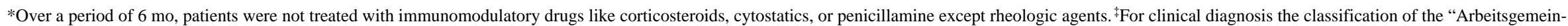

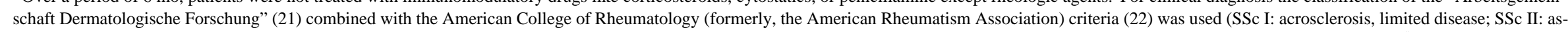

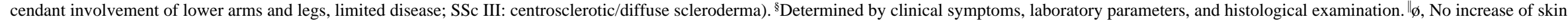

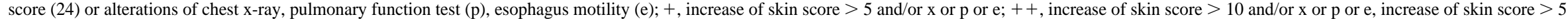

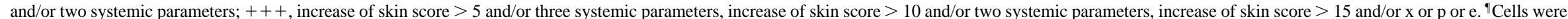

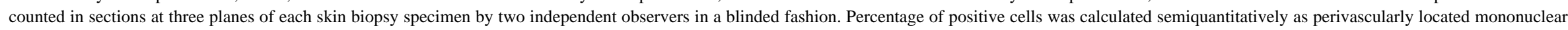

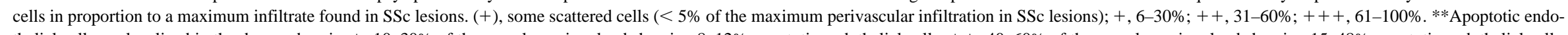

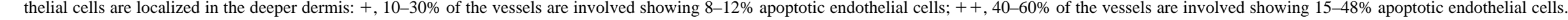

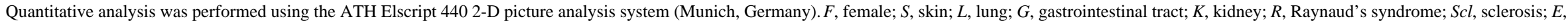
edema. 

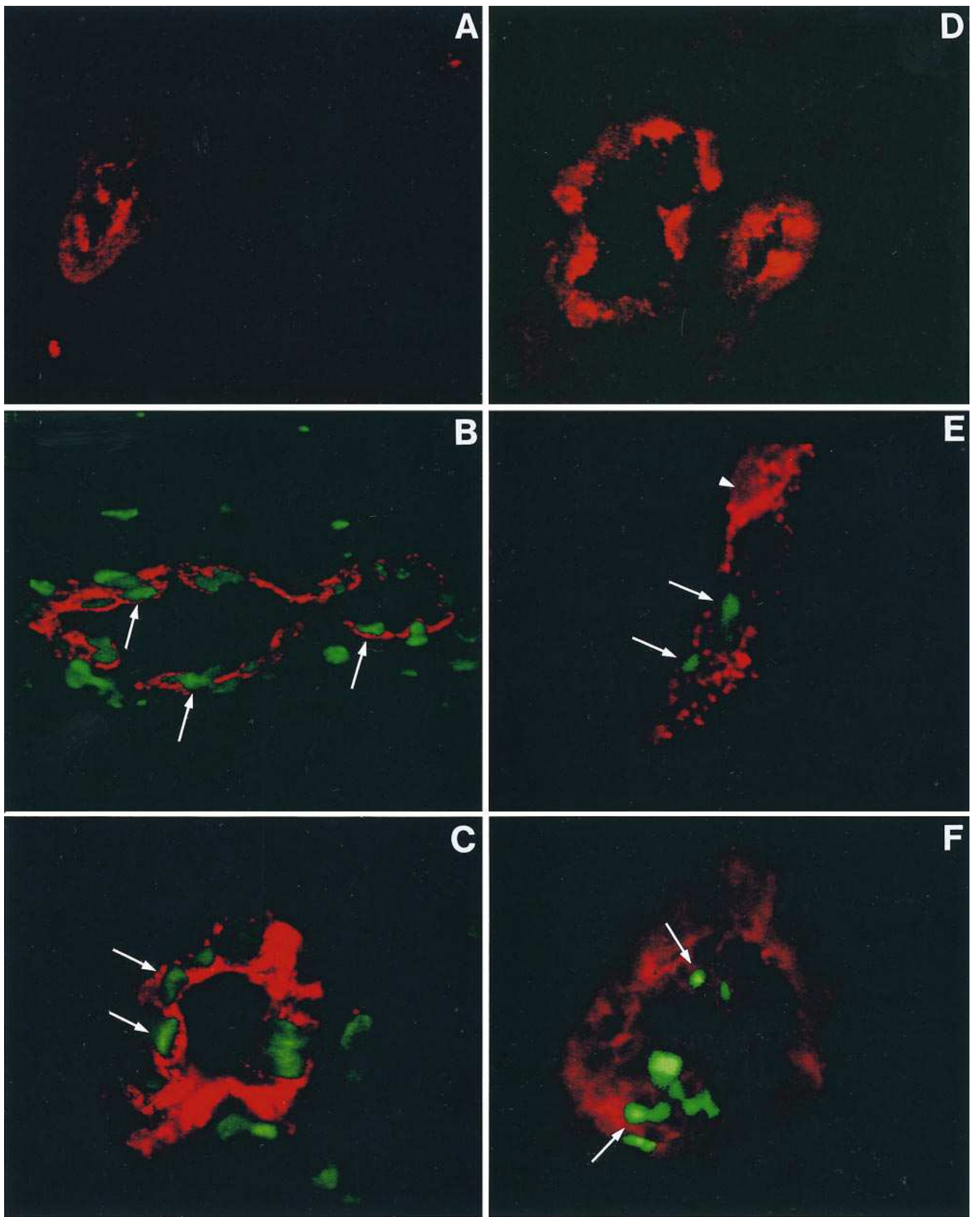

Figure 2. Simultaneous determination of endothelial cells and apoptosis on $4-\mu \mathrm{m}$ frozen skin sections. The apoptotic cells reveal a green-stained nucleus after $3^{\prime} \mathrm{OH}$ labeling by the TUNEL technique. The sections were double stained by indirect immunofluorescence using a rabbit antivWf antibody and an anti-rabbit TRITC-conjugate to detect endothelial cells. Note that only healthy, nonapoptotic endothelial cells (red) are found in the controls: $(A)$ keloid, $(D)$ UCD-058. (E) Staining of UCD-200 comb section in the early stage with no macroscopic alterations showing endothelial cells to be the first to undergo apoptosis: apoptotic endothelial cells in red with a green nucleus (arrows), healthy endothelial cell in red (arrowhead). $(B)$ loSc, $(C)$ SSc, and $(F)$ UCD-200 at a disease stage comparable with early-edematous, acute human SSc shown in $C$, also show apoptotic endothelial cells (arrows) (original magnification $\times 63$ oil; $\times 40$ zoom). 
Table II. Characterization of Apoptotic Cells in the Comb of UCD-200/206 Chickens

\begin{tabular}{|c|c|c|c|c|c|c|c|c|c|c|}
\hline Strain & Clinical stage* & $\mathrm{ap} / \mathrm{vWf}$ & $\mathrm{CD} 4$ & $\mathrm{ap} / \mathrm{CD} 4^{\ddagger}$ & CD8 & $\mathrm{ap} / \mathrm{CD} 8^{\ddagger}$ & TCR1 & ap/TRC1 $1^{\ddagger}$ & ap $/$ Coll. I $^{\$}$ & $\mathrm{ap} / \|^{\|}$ \\
\hline NWL & Healthy & $0^{\mathbb{I}} 10 * *$ & $6 / 10$ & $0 / 10$ & $0 / 10$ & $0 / 10$ & $0 / 10^{\text {辣 }}$ & $0 / 10$ & ND & $0 / 10$ \\
\hline UCD-058 & Healthy & $0 / 13$ & $8 / 13$ & $7 / 13$ & $0 / 13$ & $0 / 13$ & $13 / 13^{\text {蟆 }}$ & $0 / 13$ & $0 / 2$ & $0 / 13$ \\
\hline \multirow[t]{4}{*}{ UCD-200 } & - & $8 / 9$ & $4 / 6$ & $0 / 6$ & $0 / 6$ & $0 / 6$ & $6 / 6^{\text {क* }}$ & $0 / 6$ & $0 / 2$ & $0 / 9$ \\
\hline & + & $13 / 13$ & $10 / 10$ & $0 / 10$ & $2 / 10$ & $0 / 10$ & $10 / 10^{\S \S}$ & $0 / 10$ & $0 / 4$ & $13 / 13$ \\
\hline & ++ & $13 / 13$ & $9 / 9$ & $1 / 9$ & $5 / 9$ & $0 / 9$ & $9 / 9^{\S \S}$ & $0 / 9$ & $1 / 5$ & $13 / 13$ \\
\hline & +++ & $18 / 18$ & $7 / 7$ & $0 / 7$ & $6 / 7$ & $0 / 7$ & $7 / 7^{\S \S}$ & $0 / 7$ & $2 / 2$ & $18 / 18$ \\
\hline \multirow[t]{4}{*}{ UCD-206 } & - & $4 / 4$ & $4 / 4$ & $0 / 4$ & $0 / 4$ & $0 / 4$ & $4 / 4$ 蛙 & $0 / 4$ & $0 / 2$ & $0 / 4$ \\
\hline & + & $3 / 3$ & $3 / 3$ & $0 / 3$ & $0 / 3$ & $0 / 3$ & $3 / 3^{\S \S}$ & $0 / 3$ & $0 / 2$ & $3 / 3$ \\
\hline & ++ & $3 / 3$ & $3 / 3$ & $0 / 3$ & $0 / 3$ & $0 / 3$ & $3 / 3^{\S \S}$ & $0 / 3$ & $0 / 2$ & $3 / 3$ \\
\hline & +++ & $3 / 3$ & $3 / 3$ & $0 / 3$ & $2 / 3$ & $0 / 3$ & $3 / 3^{\S \S}$ & $0 / 3$ & $3 / 3$ & $3 / 3$ \\
\hline
\end{tabular}

*Clinical stage was classified as follows:,- no macroscopic alterations; + , erythema; ++ , erythema and edema; +++ , degenerative lesions; ${ }^{*}$ Double staining with FITC-TUNEL for apoptosis and visualization of respective cell marker with TRITC-labeled antibodies. ${ }^{8}$ Collagen type I as a marker for fibroblasts. ${ }^{\| A p o p-}$

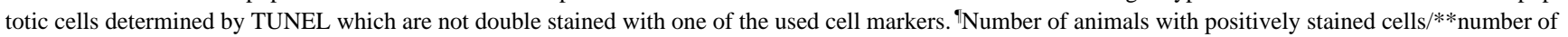
animals analyzed. ${ }^{*}$ TCR1 positive cells are localized only in the papillary dermis. ${ }^{\S}{ }^{\$} \mathrm{TCR} 1$ positive cells found in all dermal layers. ND, not determined.
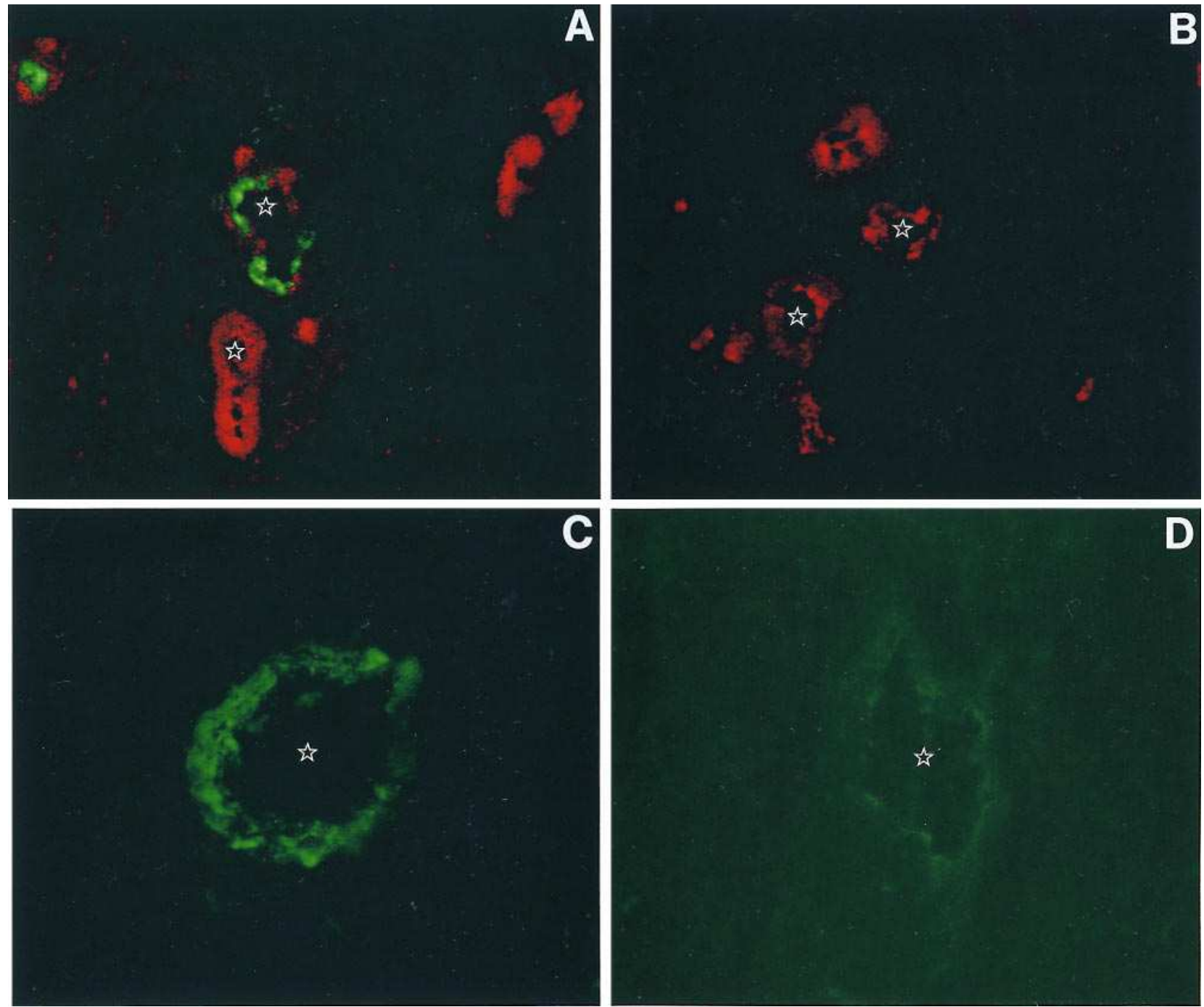

Figure 3. Ig-staining of endothelial cells on frozen comb sections with anti-chicken Ig-FITC (green) and anti-vWf-TRITC (red): ( $A$ ) UCD-200 in the early stage of disease: $\mathrm{Ig}^{+}$staining (green) of endothelium (red), $(B)$ endothelium of healthy UCD-058 is Ig negative. Detection of serum AECA by indirect immunofluorescence tests on NWL comb sections: $(C)$ UCD-200 shows strong staining of endothelium, $(D)$ UCD-058 serum is negative for AECA (original magnification $\times 63$ oil; $\times 20$ zoom). Lumen of vessels is indicated by stars. 
ber at $55^{\circ} \mathrm{C}$, the TUNEL reaction was carried out by incubating the sections with $15 \mu \mathrm{l} 0.6 \mu \mathrm{M}$ FITC-12-dUTP (Boehringer Mannheim, Mannheim, Germany), $60 \mu \mathrm{M}$ dATP, $1 \mathrm{mM} \mathrm{CoCl} 2,30 \mathrm{mM}$ Tris, $\mathrm{pH}$ $7.2,140 \mathrm{mM}$ sodium cacodylate, and $25 \mathrm{U}$ terminal deoxynucleotidyl transferase (Boehringer Mannheim) covered with a plastic cover slip $\left(1 \mathrm{~h}\right.$ at $\left.37^{\circ} \mathrm{C}\right)$. The reaction was stopped with Tris/EDTA, $\mathrm{pH} 8(5$ min). The sections were washed twice in TBS and mounted with Mowiol (Hoechst, Frankfurt, Germany).

Detection of AECA. 4- $\mu \mathrm{m}$ frozen, unfixed comb sections from UCD200/206 or control chickens were incubated for 60 min with FITCconjugated goat anti-chicken Ig, washed for $60 \mathrm{~min}$ in PBS, incubated for 30 min with rabbit anti-vWf, washed, incubated with TRITC-conjugated swine anti-rabbit Ig, washed, and mounted with Mowiol.

To analyze AECA in chicken serum, frozen skin sections of NWL chickens were incubated for 90 min with the serum, diluted 1:3 in $\mathrm{PBS} / 1 \% \mathrm{BSA}$, washed for $60 \mathrm{~min}$ in PBS, incubated with FITC-conjugated goat anti-chicken Ig for $60 \mathrm{~min}$, washed for $60 \mathrm{~min}$ in PBS, and mounted with Mowiol.

Microscopic analysis. Slides were analyzed using a Zeiss LSM 10 laser scanning microscope. Digital images of fluorescence in response to excitation with the helium neon laser $(543 \mathrm{~nm})$, filter setting BP 575-640 for cells stained with TRITC, and the argon laser (488 nm), filter setting BP 530/30 for FITC-stained cells, were collected at a scan rate of $2 \mathrm{~s}$ per image. Digital images were stored on a hard disk, transferred to a high-resolution RGB color video photomonitor (Lucius and Baer, Geretsried, Germany), and photographed using Fujicolor Super HG 200 film. The data were analyzed quantitatively using the Elscript 440 2-D picture analysis program (ATH, Munich, Germany) which was upgraded for determination of positive cells in the percentage of the total area.

\section{Results}

Skin biopsies from $15 \mathrm{SSc}$ patients at different disease stages (7 early-edematous, acute, 8 chronic-sclerotic), 9 patients with loSc, 3 patients with keloids, and 8 healthy controls, as well as 73 UCD-200/206 chickens and 23 healthy control chickens, were used to analyze the mechanism responsible for the degenerative skin lesions in SSc. Detection of apoptotic cells by TUNEL (25) on frozen tissue sections indicated the presence of apoptotic cells in the deeper dermis of all patients with acute SSc and loSc samples (Table I). The eight chronic, fibrotic SSc biopsies, the healthy controls, and keloid sections

Table III. Ig Staining in the Comb of UCD-200/206 Chickens

\begin{tabular}{lccc}
\hline \multicolumn{1}{c}{ Strain } & Clinical stage* & $\mathrm{Ig}^{\ddagger}$ & $\mathrm{Ig} / \mathrm{vWf}$ \\
\hline NWL & Healthy & $0 / / 2^{\sharp 1}$ & $0 / 2$ \\
UCD-058 & Healthy & $0 / 9$ & $0 / 9$ \\
UCD-200 & - & $6 / 7$ & $6 / 7$ \\
& + & $7 / 8$ & $7 / 8$ \\
& ++ & $8 / 9$ & $8 / 9$ \\
& +++ & $7 / 7$ & $7 / 7$ \\
UCD-206 & - & $3 / 4$ & $3 / 4$ \\
& + & $2 / 3$ & $2 / 3$ \\
& ++ & $3 / 3$ & $3 / 3$ \\
& +++ & $3 / 3$ & $3 / 3$
\end{tabular}

Direct immunofluorescence test on frozen, unfixed sections of comb skin. *Clinical stage classified as in Table II. ${ }^{*} \mathrm{Ig}$ positive nonendothelial cells in direct immunofluorescence. ${ }^{\S}$ Double staining for Ig (FITC) and vWf (TRITC). "Number of animals with positively stained cells. " $\mathrm{Num}$ ber of animals analyzed. showed no apoptotic cells (Fig. $2 A$ ). Double staining with vWf, a marker for endothelial cells, revealed that most of the apoptotic cells in the deeper dermis were endothelial cells (Fig. 2, $B$ and $C$ ). As in the comparable stage of avian scleroderma, infiltrating lymphocytes are also undergoing apoptosis. All UCD-200/206 samples, already in an early stage of the disease, before clinical manifestations are visible, a stage which is not accessible in patients, also showed apoptotic cells in the deeper dermis. Simultaneous characterization of these cells by indirect immunofluorescence staining clearly revealed that endothelial cells are the first to undergo apoptosis in the skin of UCD-200/206 chickens (Fig. 2, $E$ and $F$ ). In this early phase of the disease, no other alterations are seen microscopically compared with healthy NWL and UCD-058 control chickens. TCR $1^{+}$lymphocytes were located only in the papillary dermis, and a few $\mathrm{CD}^{+}$cells were found in some specimens of both diseased animals and controls. With disease progression, $\mathrm{TCR}^{+}$cells, $\mathrm{CD}^{+}$, and $\mathrm{CD}^{+}$lymphocytes infiltrated perivascularly in all dermal layers, and expression of vWf, also a marker for endothelial cell injury, was elevated (data not shown), as were the numbers of apoptotic endothelial cells. In the subsequent stages, lymphocytes, fibroblasts, and cells that could not be identified with available antibodies in the avian system died also by apoptosis. In control animals, no cells underwent apoptosis (Fig. 2 D) except $\mathrm{CD}^{+}$cells, which are sometimes found in the vicinity of papillary vessels, probably due to mechanical microinjuries to the comb. These data are summarized in Table II.

Double staining of the skin sections suggests that neither $\mathrm{TCR} 1^{+}, \mathrm{CD}^{+}{ }^{+}$, nor $\mathrm{CD} 8^{+}$lymphocytes induce apoptosis in endothelial cells since they are not in close proximity to the latter. This apoptotic process seems rather to be induced by AECA, as shown by anti-Ig staining of endothelial cells on UCD-200/206 skin sections (Fig. 3 A). Antibodies specific for endothelial cells were detected in the serum of all UCD-200/

Table IV. AECA in UCD-200/206 Chicken Serum

\begin{tabular}{lcc}
\hline \multicolumn{1}{c}{ Strain } & Clinical stage* & AECA \\
\hline NWL & Healthy & $0 \% / 8$ \\
UCD-058 & Healthy & $0 / 9$ \\
OS & TI $+/ A b-$ & $0 / 3$ \\
OS & TI $+/ A b+$ & $0 / 3$ \\
UCD-200 & - & $2 / 2$ \\
& + & $8 / 8$ \\
& ++ & $9 / 9$ \\
UCD-206 & +++ & $7 / 7$ \\
& - & $4 / 4$ \\
& + & $3 / 3$ \\
& ++ & $3 / 3$ \\
& +++ & $3 / 3$ \\
\hline
\end{tabular}

AECA determined by indirect immunofluorescence test on frozen, unfixed sections of NWL comb skin. *Clinical stage classified as in Table II. OS chickens, a model for Hashimoto thyroiditis, were used as additional control: $\mathrm{TI}+/ \mathrm{Ab}-$, severe thyroid infiltration, antithyroglobulin antibody negative; $\mathrm{TI}+/ \mathrm{Ab}+$, severe thyroid infiltration, antithyroglobulin antibody positive. ${ }^{*}$ Number of animals with positively stained cells. ${ }^{\S}$ Number of animals analyzed. 
206 chickens by indirect immunofluorescence on NWL skin sections (Fig. 3 C). The healthy NWL and UCD-058 controls as well as OS chickens, an unrelated model for autoimmune Hashimoto thyroiditis (19), were AECA negative (Fig. 3, B and $D$ ). Data from 44 UCD-200/206 chickens, 6 OS chickens, and 17 healthy controls analyzed for AECA are summarized in Tables III and IV.

\section{Discussion}

The investigations described herein were designed to determine the mechanism underlying the degenerative skin lesions in SSc. The use of UCD-200/206 chickens, a well-established model of human scleroderma, made it possible to analyze the early stage of the disease, before clinical manifestations are established. Analysis of skin biopsies from SSc patients showed no differences from comparable disease stages of UCD-200/ 206 chickens, suggesting a similar pathogenesis. As in the comparable acute, edematous stage of avian scleroderma, infiltrating lymphocytes are undergoing apoptosis during disease progression, thus explaining the lack of perivascular lymphocytes in the chronic-sclerotic stage of disease. In contrast to general belief, the first observed event was not infiltration by $\mathrm{CD}^{+}$or TCR $1^{+}$lymphocytes, but induction of apoptosis in endothelial cells, possibly mediated by AECA. Although AECA have been demonstrated in the serum of SSc patients $(26,27)$ only one, recently published paper, shows a possible pathogenetic role of AECA in scleroderma (28). These authors showed in vitro an increased adhesion of U937 monocytic cells to AECA pretreated human umbilical vein endothelial cells accompanied by increased adhesion molecule expression and IL-1 production. The mechanism of cytotoxicity of AECA positive scleroderma sera was thought to be antibody-dependent cellular cytotoxicity, since sera alone were not cytotoxic on umbilical vein or microvascular endothelial cells in vitro $(29,30)$. The activity resided in $\mathrm{IgG}$ fractions, and the responsible effector cells were Fc receptor positive (31). It is also interesting to note that anticardiolipin antibodies have been reported to exert antiendothelial reactivity (32). However, none of these studies could demonstrate in situ the role of AECA in SSc pathogenesis. Using the TUNEL technique, modified by us for this purpose (25), we were able to show in situ that, at the initial phase of SSc and loSc, endothelial cells undergo apoptosis contributing to similar pathogenetic events in the fibrosis of both entities. The role of inflammatory cells in the induction and/or perpetuation of apoptotic processes remains unclear. The positive staining of microvessels for $\mathrm{Ig}$ and the finding of neighboring $\mathrm{Ig}^{+}$nonendothelial cells in some cases support the hypothesis of AECA-mediated vascular damage through antibody-dependent cellular cytotoxicity. Analysis of the potential effect of UCD-200/206 chicken and human SSc sera in vitro on microvascular endothelial cells is obviously crucial and will be performed in the course of a long-term follow-up study.

\section{Acknowledgments}

We thank O. Vainio and R. Timpl for providing antibodies.

This work was supported by the Austrian Research Council (project No. 10830) and the "Bundesministerium für Forschung und Technologie" (BMFT project No. 89030).

\section{References}

1. Haynes, D.C., and M.E. Gershwin. 1982. The immunopathology of progressive systemic sclerosis (PSS). Semin. Arthritis Rheum. 11:331-351.

2. Krieg, T., and M. Meurer. 1988. Systemic scleroderma. Clinical and pathophysiologic aspects. J. Am. Acad. Dermatol. 18:457-481.

3. Black, C.M. 1993. The aetiopathogenesis of systemic sclerosis. J. Intern. Med. 234:3-8

4. Fleischmajer, R. 1995. Localized and systemic scleroderma. In Connective Tissue Diseases of the Skin. C.M. Lapière and T. Krieg, editors. Marcel Dekker, Inc., New York. 295-314.

5. Russel, M.L. 1983. The tight-skin mouse: is it a model for scleroderma? J. Rheumatol. 10:679-688.

6. Jimenez, S.A., A. Millan, and R.I. Bashey. 1984. Scleroderma-like alterations in collagen metabolism occurring in the TSK (tight-skin) mouse. Arthritis Rheum. 27:180-185.

7. Gershwin, M.E., H. Abplanalp, R.M. Castles, J. Ikeda, J. Van De Water, J. Eklund, and D. Haynes. 1981. Characterization of a spontaneous disease of white leghorn chickens resembling progressive systemic sclerosis (scleroderma). J. Exp. Med. 153:1640-1659.

8. Van De Water, J., M.E. Gershwin, H. Abplanalp, G. Wick, and K. von der Mark. 1984. Serial observations and definition of mononuclear cell infiltrates in avian scleroderma, an inherited fibrotic disease of chickens. Arthritis Rheum. 27:807-815.

9. Wilson, T.J., J. Van De Water, F.C. Mohr, R.L. Boyd, A. Ansari, G. Wick, and M.E. Gershwin. 1992. Avian scleroderma: evidence for qualitative and quantitative T cell defects. J. Autoimmun. 5:261-276.

10. Van De Water, J., and M.E. Gershwin. 1986. Avian scleroderma. An inherited fibrotic disease of White Leghorn chickens resembling progressive systemic sclerosis. Am. J. Pathol. 120:478-482.

11. Van De Water, J., L. Haapanen, R. Boyd, H. Abplanalp, and M.E. Gershwin. 1989. Identification of T cells in early dermal lymphocytic infiltrates in avian scleroderma. Arthritis Rheum. 32:1031-1040.

12. Gruschwitz, M.S., Y. Shoenfeld, M. Krupp, M.E. Gershwin, E. Penner, H.-P. Brezinschek, and G. Wick. 1993. Antinuclear antibody profile in UCD line 200 chickens: a model for progressive systemic sclerosis. Int. Arch. Allergy Immunol. 100:307-313.

13. Gruschwitz, M., S. Moormann, H. Dietrich, R. Timpl, A. Colombatti, and G. Wick. 1992. Distribution of matrix proteins in the skin of UCD 200 chickens: a model for progressive systemic sclerosis. Arch. Dermatol. Res. 284:64a. (Abstr.)

14. Gruschwitz, M.S., S. Moormann, G. Krömer, R. Sgonc, H. Dietrich, G. Boeck, M.E. Gershwin, R. Boyd, and G. Wick. 1991. Phenotypic analysis of skin infiltrates in comparison with peripheral blood lymphocytes, spleen cells and thymocytes in early avian scleroderma. J. Autoimmun. 4:577-593.

15. Prescott, R.J., A.J. Freemont, C.J. Jones, J. Hoyland, and P. Fielding. 1992. Sequential dermal microvascular and perivascular changes in the development of scleroderma. J. Pathol. 166:255-263.

16. Kahaleh, B. 1993. Immunologic aspects of scleroderma. Curr. Opin. Rheumatol. 5:760-765.

17. Blann, A.D., K. Illingworth, and M.I. Jayson. 1993. Mechanisms of endothelial cell damage in systemic sclerosis and Raynaud's phenomenon. $J$. Rheumatol. 20:1325-1330.

18. Abplanalp, H., M.E. Gershwin, E. Johnston, and J. Reid. 1990. Genetic control of avian scleroderma. Immunogenetics. 31:291-295.

19. Wick, G., K. Hála, H.P. Brezinschek, H. Dietrich, H. Wolf, and G. Kroemer. 1989. The obese strain (OS) of chicken: an animal model for spontaneous autoimmune thyroiditis. Adv. Immunol. 47:433-500.

20. Dietrich, H.M. 1989. Housing, breeding and selecting chickens of the obese strain (OS) with spontaneous autoimmune thyroiditis. Lab. Anim. 23: $345-352$.

21. "Arbeitsgruppe Sklerodermie" der Arbeitsgemeinschaft Dermatologische Forschung (ADF). 1986. Klinik der progressiven systemischen Sklerodermie (PSS). Hautarzt. 37:320-324.

22. Subcommittee for Scleroderma Criteria of the American Rheumatism Association Diagnostic and Therapeutic Criteria Committee. 1980. Preliminary criteria for the classification of systemic sclerosis (scleroderma). Arthritis Rheum. 23:581-590.

23. Gruschwitz, M.S., O.P. Hornstein, and P. von den Driesch. 1995. Correlation of soluble adhesion molecules in the peripheral blood of scleroderma patients with their in situ expression and with disease activity. Arthritis Rheum. 38: $184-189$.

24. Kahaleh, M.B., G.L. Sultany, E.A. Smith, J.E. Huffstutter, C.B. Loadholt, and E.C. LeRoy. 1986. A modified scleroderma skin scoring method. Clin. Exp. Rheumatol. 4:367-369.

25. Sgonc, R., G. Boeck, H. Dietrich, J. Gruber, H. Recheis, and G. Wick. 1994. Simultaneous determination of cell surface antigens and apoptosis. Trends Genet. 10:41-42.

26. Rosenbaum, J., B.E. Pottinger, P. Woo, C.M. Black, S. Loizou, M.A. Byron, and J.D. Pearson. 1988. Measurement and characterization of circulating anti-endothelial cell IgG in connective tissue diseases. Clin. Exp. Immunol. 72:450-456. 
27. Yoshio, T. 1993. Anti-endothelial cell antibodies. Rinsho. Byori. 41:851858

28. Carvalho, D., C.O. Savage, C.M. Black, and J.D. Pearson. 1996. IgG anti-endothelial cell autoantibodies from scleroderma patients induce leukocyte adhesion to human vascular endothelial cells in vitro. Induction of adhesion molecule expression and involvement of endothelium-derived cytokines. $J$. Clin. Invest. 97:111-119.

29. Marks, R.M., M. Czerniecki, B.S. Andrews, and R. Penny. 1988. The effects of scleroderma serum on human microvascular endothelial cells. Induction of antibody-dependent cellular cytotoxicity. Arthritis Rheum. 31:15241534.
30. Holt, C.M., N. Lindsey, J. Moult, R.G. Malia, M. Greaves, A. Hume, N.R. Rowell, and P. Hughes. 1989. Antibody-dependent cellular cytotoxicity of vascular endothelium: characterization and pathogenic associations in systemic sclerosis. Clin. Exp. Immunol. 78:359-365.

31. Penning, C.A., J. Cunningham, M.A. French, G. Harrison, N.R. Rowell, and P. Hughes. 1984. Antibody-dependent cellular cytotoxicity of human vascular endothelium in systemic sclerosis. Clin. Exp. Immunol. 57:548-556.

32. Vismara, A., P.L. Meroni, A. Tincani, E.N. Harris, W. Barcellini, A. Brucato, M. Khamashta, G.R.V. Hughes, C. Zanussi, and G. Balestrieri. 1988. Relationship between anti-cardiolipin and anti-endothelial cell antibodies in systemic lupus erythematosus. Clin. Exp. Immunol. 74:247-253. 